\title{
Review
}

\section{Prospects for gene therapy of insulin-dependent diabetes mellitus}

\author{
S. Efrat \\ Department of Molecular Pharmacology, Albert Einstein College of Medicine, Bronx, New York, USA and \\ Department of Human Genetics and Molecular Medicine, Sackler School of Medicine, Tel Aviv University, Tel Aviv, Israel
}

\begin{abstract}
Summary The application of gene therapy to Type I (insulin-dependent) diabetes mellitus awaits improvements in gene transfer technologies and the development of better tools for accurate diagnosis of pre-diabetic people. Identification of the most promising candidate genes for gene transfer requires further elucidation of the molecular events involved in beta-cell autoimmune destruction, islet ontogeny and differentiation, and beta-cell function. This review outlines a number of possible targets for gene therapy in Type I diabetes, which could help prevent
\end{abstract}

the autoimmune damage to islets, induce islet regeneration, and restore insulin production through engineering of self non-beta cells or beta-cell transplantation. It also evaluates their potential merits and drawbacks. [Diabetologia (1998) 41: 1401-1409]

Keywords Beta-cell lines, conditional transformation, gene transfer, glucose-regulated promoters, immunomodulation, insulin biosynthesis, insulin secretion, islet regeneration, proinsulin processing, transplantation

\section{Introduction}

Human gene therapy, pioneered in the early years of this decade, holds the promise of revolutionizing the treatment of genetic diseases. By modifying the genetic make up of somatic cells, the missing or abnormal cell function caused by the inheritance of a mutant gene can be corrected through introduction of a normal copy of the gene. Despite considerable progress in the development of gene transfer technologies, however, no human disease has been cured yet by gene therapy. Human gene therapy is still facing fundamental challenges, most of which are centred on the development of safe and efficient vectors $[1,2]$.

Corresponding author: Dr. S. Efrat, Dept. of Human Genetics and Molecular Medicine, Sackler School of Medicine, Tel Aviv University, Ramat Aviv, Tel Aviv, 69978, Israel Abbreviations: CTLA4, cytotoxic T lymphocyte-associated antigen 4; E3, early region 3 of adenovirus; IL, interleukin; iNOS, inducible nitric oxide synthase; LCMV, lymphocytic choriomeningitis virus; NO, nitric oxide; NOD, nonobese diabetic; RIP, rat insulin II promoter; SOD, superoxide dismutase; Tag, T antigen; tet, tetracycline; TNF $\alpha$, tumor necrosis factor $\alpha$.
In principle, gene transfer can be carried out in vivo, by introducing the gene into the patient using a viral vector, or a non-viral agent such as liposomes or ex vivo by modification of cells explanted from the patient, which are subsequently implanted back into the patient. With the emergence of improved methods for cell encapsulation, foreign cells expressing the normal gene, either naturally or following genetic engineering, are also being considered in designing gene therapy approaches. Each of these strategies faces its own set of hurdles. Gene transfer in vivo requires dependable means for cell-specific targeting of the vector. In targeting dividing cells, stable integration of the targeted gene is needed, and it should occur without disruption of endogenous genes. The targeted gene must be expressed at sufficient levels over a long period of time. The gene product, as well as proteins derived from the viral vector, should avoid eliciting an immune response, that over time can diminish the expression of the introduced gene. Gene transfer in vitro has the advantages of exposing only a small number of the patient's cells to the genetic manipulation, requiring lower virus titers for infection, and allowing careful examina- 
tion of cell function and genetic stability before re-introduction into the patient. On the other hand, this approach is limited to those few cell types that can be easily explanted and implanted, either in their tissue of origin or in a different location.

Type I (insulin-dependent) diabetes mellitus, caused by the autoimmune destruction of the insulin-producing pancreatic islet beta cells, is a clear candidate for gene therapy. The current treatment of Type I diabetes relies on insulin supplementation, coupled with close monitoring of blood glucose concentrations. The Diabetes Control and Complications Trial (DCCT) has established that tight control of glycaemia can prevent or appreciably reduce the incidence of the long-term complications associated with Type I diabetes [3]. Relatively few patients are capable, however, of complying with the strict regimens required for achieving euglycaemia with openloop insulin treatment. Insulin infusion pumps, regulated by glucose sensing devices, could in the future offer a more convenient and accurate alternative to these regimens. It is widely accepted, however, that the optimal treatment of Type I diabetes would consist of a source of cells which can produce insulin and release it in a highly regulated way. The patient's own cells would seem the optimal source since they avoid issues of graft rejection. Engineering insulin secretion in the patient's non-beta cells would evade the recurring autoimmunity to beta cells. By developing ways to prevent the autoimmune destruction of beta cells it could become possible to save the primary islets of pre-diabetic people, given early diagnosis. In patients with overt diabetes, induction of islet regeneration could help replace the damaged islets, provided that recurring autoimmunity can be blocked. Alternatively insulin-secreting cells, either beta cells or engineered non-beta cells, from an exogenous source, could be used for transplantation into Type I diabetes patients. The prospects for such novel therapies have been advanced by recent progress in our understanding of normal beta-cell biology and its pathology in Type I diabetes. These future therapeutic strategies will rely to a large extent on genetic alterations of beta cells and other cell types. This article provides an overview of the various approaches for achieving euglycaemia through genetic manipulations as reflected in studies of animal models and examines their promises and shortcomings, as well as their potential risks.

\section{Prevention of Type I diabetes}

In principle the best approach for treatment of Type I diabetes would consist of identifying people at risk of developing the disease and treating them to prevent the islet damage. This prospect depends on the development of highly reliable tools for diagnosis of pre- diabetic people, and a better understanding of the mechanisms of beta-cell autoimmune destruction.

The aetiology of Type I diabetes is still not known. In the nonobese diabetic (NOD) mouse model, at least 15 chromosomal loci have been implicated in determining susceptibility to the disease [4]. Thus at present, no single mutant Type I diabetes gene is known whose replacement with a normal allele through gene therapy would reverse the course of the disease, unlike the case in many other human genetic diseases that are caused by mutations in a single gene. In both humans and mice, certain alleles of the class II major histocompatibility complex (MHC) are strongly associated with development of Type I diabetes [5, 6]. Environmental factors such as infectious agents, chemicals and stress, are, however, likely to play an important part, as demonstrated by a concordance rate of only $50 \%$ for development of the disease among monozygotic twins [7]. Although a number of candidate antigenic targets for the autoimmunity have been identified [6], it is not clear whether any of them play a crucial part in initiating the autoimmune response. Identification of one or several such primary targets could allow the development of immunotherapy by induction of antigen-specific tolerance. One of the candidate antigens is insulin itself and a clinical prevention trial involving tolerization to insulin is currently in progress [8].

With our developing understanding of the mechanisms by which autoimmunity destroys the beta cells, a number of genes have been considered for increasing the resistance of beta cells to the immune attacks or locally inhibiting the immune effector cells. These genetic manipulations would only be useful if done as a prophylactic treatment, at a time when the majority of beta cells are still intact and the person being treated is healthy. Thus a pre-condition for such manipulations is a reliable method for identification of people at risk for developing Type I diabetes with a high degree of certainty. Screening of first-degree relatives of diabetic patients has been useful, however, most of the new Type I diabetes cases are not familial. Genotyping of the DQ and DR class II MHC genes has some predictive value as certain alleles at these loci are highly associated with Type I diabetes $[5,6,8]$. The use of serological tests for a battery of anti-islet cell autoantibodies (ICA) has also shown some predictive promise $[6,8$, 9]. None the less, the combination of these two screening tools does not yet provide the degree of certainty needed to justify relatively invasive and risky interventions, such as gene therapy, in healthy people. Thus, in vivo gene therapy with the genes described below is not a realistic prospect before significant improvements are made in both early diagnosis of Type I diabetes and the efficiency of gene transfer in vivo. Some of these genes may, however, be useful in ex vivo engineering of beta cells for transplanta- 
tion, to increase their chance for survival in the autoimmune environment.

A major mechanism responsible for the autoimmune destruction of beta cells involves the induction of apoptosis by cytokines, such as interleukin (IL)$1 \beta$, tumour necrosis factor $\alpha$ (TNF $\alpha)$, and gamma interferon which are secreted in the vicinity of the islets by activated $\mathrm{T}$ lymphocytes. Overexpression of antiapoptosis genes by gene delivery into pre-diabetic islets in vivo could increase beta-cell resistance to cytokines. The potential of this approach was shown by expression of the anti-apoptosis gene bcl-2 in betacell lines, which resulted in increased cell resistance to cytokines in tissue culture $[10,11]$. Overexpression of bcl-2 does not seem to affect beta-cell function. It might contribute, however, to unregulated beta-cell replication in response to immortalizing or transforming agents.

Cytokine-induced beta-cell apoptosis is mediated through raised expression of nitric oxide synthase (iNOS) and an intracellular increase in nitric oxide (NO) free radicals $[12,13]$. Beta cells express normally very low levels of enzymes capable of inactivating free radicals, which renders them highly susceptible to their damage. By increasing the activity of such enzymes in beta cells, cell survival could be improved. Overexpression of the radical scavenging enzyme copper/zinc superoxide dismutase (SOD) in beta cells in transgenic mice enhanced their resistance to oxidative stress induced by treatment with alloxan and streptozotocin [14]. In a more recent study, overexpression of the manganese SOD (MnSOD) gene in INS- 1 cells resulted in reduction in IL- $1 \beta$-induced iNOS and NO concentrations and provided protection against cell death induced by the cytokine [15]. It remains to be shown whether SOD overexpression in beta cells has any deleterious effects on insulin production and regulated secretion.

The use of genes evolved by viruses to evade immune responses against virus-infected cells has shown promise in both facilitation of allogeneic islet transplantation and the prevention of autoimmunity against beta cells in a mouse model. The early 3 (E3) region of adenoviruses encodes several proteins that downregulate class I MHC-mediated antigen presentation on the cell surface and provide protection from $\mathrm{TNF} \alpha$-induced apoptosis [16]. Expression of the E3 genes in beta cells in transgenic mice, denoted RIP-E3, enabled transplantation of islets from these mice into allogeneic strains without appreciable rejection [17]. Moreover, by crossing the RIP-E3 mice into a mouse model of autoimmune diabetes, the RIP-LCMV mice, the E3 genes were shown to provide protection against the autoimmune destruction of beta cells [18]. The RIP-LCMV mice express antigens of the lymphocytic choriomeningitis virus (LCMV) in beta cells. Following infection with LCMV they develop autoimmunity to their beta cells, resulting in islet destruction similar to that of Type I diabetes [19]. Expression of the E3 genes in the double transgenic mice effectively prevented the islet damage. Thus, targeting the expression of the E3 genes to pre-diabetic islets could help prevent the development of Type I diabetes.

In contrast to these "defensive" approaches, a number of groups have explored ways to equip the beta cells with a more "offensive" capability to locally inactivate the immune effector cells that attack them. One approach was based on the finding that immunologically privileged organs, such as the eye and testis, express a cell surface ligand (FasL) for the Fas receptor found on activated T cells. Engagement of the receptor activates apoptosis in the T cells, thus providing protection for the cells expressing FasL. Transgenic expression of FasL on the beta-cell surface in NOD mice has been attempted to induce apoptosis in the $\mathrm{T}$ cells that infiltrate the islets [20]. Surprisingly, these mice developed diabetes at an accelerated rate, most likely due to self-destruction of beta cells following Fas induction on their cell surface during the inflammatory process. Fas-deficient NOD ${ }^{1 p r / p r}$ mice do not develop diabetes [20]. These findings are supported by other reports on transgenic FasL expression in beta cells [21, 22]. The Fas-FasL interaction therefore emerges as a mechanism for beta-cell killing in Type I diabetes, rather than one with a protective potential. Viewed in this light, inhibition of Fas expression in beta cells, for example by targeting of an antisense construct, might be considered as a possible approach for gene therapy. In contrast to its failure to protect beta cells from autoimmune destruction, FasL was shown to facilitate allogeneic islet transplantation, when expressed in syngeneic myoblasts that were included in the transplant [23].

Activation of the T-cell depends on antigenic stimulation of the T-cell receptor as well as a costimulatory signal from accessory molecules on antigen-presenting cells. In the absence of costimulation, the antigenic signal alone induces a state of anergy in the $\mathrm{T}$ cells. A well-characterized costimulation pathway involves the interaction of the $\mathrm{B} 7$ molecule with the CD28 receptor on T cells. Cytotoxic T lymphocyteassociated antigen 4 (CTLA4), a protein homologous to $\mathrm{CD} 28$, binds B7 with high affinity and interferes with the B7-CD28 interaction. Soluble fusion proteins of CTLA4 with the immunoglobulin Fc region (CTLA4-Ig) have been shown to be immunosuppressive and facilitate islet transplantation [24]. It has also been shown that CTLA4-Ig prolongs the survival of encapsulated xenogeneic islets in NOD mice [25]. The potential of CTLA4-Ig to modulate autoimmunity has been explored in experimental models of encephalomyelitis [26] and myasthenia gravis [27]. In NOD mice, treatment with CTLA4-Ig at the onset of insulitis (2-4 weeks of age) blocked the develop- 
ment of diabetes, although it did not prevent insulitis [28]. Treatment with CTLA4-Ig at later stages ( $>10$ weeks of age) had no effect. Although the B7CD28 interaction occurs among lymphoid cells, it is possible that providing pre-diabetic islet beta cells with the ability to release CTLA4-Ig locally could interfere with this interaction and help prevent betacell autoimmune destruction.

The balance between effector and suppressor $\mathrm{T}$ cells is thought to be modulated by a complex array of cytokines in a way that remains poorly understood. Expression of certain cytokines in beta cells could shift the local balance between these subsets of $\mathrm{T}$ lymphocytes towards a suppressive phenotype. One example is IL-4: transgenic expression of this cytokine in beta cells of NOD mice was shown to prevent autoimmune diabetes [29]. In contrast expression of another cytokine, IL-10, led to conflicting results [30], causing both a delay in the onset and a reduction in the incidence of diabetes when given to adult NOD mice and an accelerated disease when transgenically expressed in beta cells, reflecting perhaps a difference between systemic and local effects. These results suggest that more work is needed to elucidate the complex cytokine effects before their rational manipulation becomes possible.

It is conceivable that a combination of genetic modifications, providing the beta cells with both "defensive" and "offensive" capabilities, will eventually be required to prevent their autoimmune destruction.

\section{Regeneration of the beta-cell mass}

Patients with overt diabetes will obviously not benefit from the preventive gene therapy approaches described above which are designed to save beta cells that have not yet been destroyed. An attractive prospect to be explored in late stage Type I diabetes is beta-cell regeneration from islet cell precursors. This prospect depends on the identification of factors that induce beta-cell neogenesis and replication as well as on the development of ways to prevent recurring autoimmunity against the newly formed islets.

In recent years impressive progress has been made in our understanding of the genes and factors involved in islet cell ontogeny and differentiation [31]. Substantial evidence supports the development of islet cell precursors from the epithelial cells of pancreatic ducts [32-35]. This process is not restricted to the development of the embryonic pancreas. Severe injury to the adult pancreas in a number of experimental models, including partial pancreatectomy [36], duct ligation [37], and transgenic expression of gamma-interferon [38], was shown to induce de novo islet formation from duct cells. Several growth factors are known to be mitogenic to duct cells. These include vascular endothelial growth factor (VEGF)
[39], islet neogenesis-associated protein (INGAP) [40], hepatocyte growth factor (HGF) [41], and Reg [42]. Their differentiation signals, however, are still not known. Members of the epidermal growth factor family, betacellulin and activin A [43], as well as HGF [44], were shown to induce trans-differentiation of an acinar cell line (AR42 J) into insulin-producing cells. Identification of factors which can induce duct cell differentiation towards the islet cell lineage could open the way for the manipulation of these factors by gene therapy for islet regeneration. It could also allow expansion of duct cells in culture and their differentiation into islet cells for transplantation.

The same principles of manipulating islet neogenesis could apply to replication of more committed cells down the islet cell lineage. At present our knowledge of islet cell renewal in the adult is very limited. Adult islet cells are constantly replaced by a slow turnover, probably from the small compartment of islet cells which maintain a replicative capacity [45]. These possibly serve as islet "stem cells", which are responsible for replenishing the adult islets with new differentiated cells, to replace those removed by apoptosis. A number of growth factors, notably lactogenic hormones, insulin-like growth factors, and members of the epidermal growth factor family, induce limited cell replication in fetal and neonatal islets in vitro [46]. It has been shown that HGF is mitogenic to cultured adult human islets [47]. These factors have, however, pleiotropic effects in vivo and cannot be simply transferred to or expressed in the pancreas without affecting other organs. Their effects in vitro do not seem to be sufficient to allow massive expansion of islet cells for transplantation. Identification of specific factors that are mitogenic to the islet "stem cells" and those affecting their differentiation into beta cells could help develop ways to expand residual islets in Type I diabetes patients, as well as for propagation of human islet cells in culture for generation of beta cells for transplantation. Genes encoding such factors could potentially be targeted to the pancreas. In such case, their expression should be regulated by inducible gene expression systems to prevent uncontrolled islet-cell proliferation.

\section{Engineering of ectopic insulin production}

The most obvious candidate for gene therapy of diabetes is the insulin gene. Engineering of ectopic insulin production and secretion in autologous non-beta cells is expected to evade immune destruction and provide a steady supply of insulin. This therapy can be applied in late stages of the disease, when few residual beta cells still exist. To successfully mimic beta-cell function, this approach needs to overcome three major obstacles: proinsulin synthesis, proinsulin processing, and mature insulin storage and regulated 
secretion. The first goal is relatively easy to achieve; preproinsulin cDNA can be expressed in heterologous cells by using appropriate cell-specific promoters. Proinsulin biosynthesis has been achieved in a variety of cell lines, for example those derived from pituitary [48] and liver [49, 50]. It has also been shown by transgenic expression in pituitary [51] and liver [52] tissues, as well as by retrovirus-mediated gene transfer into liver cells [53] and by ductal insertion of naked DNA into the exocrine pancreas and submandibular salivary gland [54]. It could also become possible to activate insulin expression in non-beta cells from the endogenous locus as shown by introduction of the gene encoding the transcription factor $\mathrm{Pd} \times 1$ into a glucagonoma cell line which resulted in activation of the insulin gene, as well as other beta-cell genes [55].

Correct proinsulin processing can be obtained in non-beta cells by introduction of minor changes in the amino acid sequence of the cleavage sites. The wild-type proinsulin sequence requires the beta-cell PC2 and PC3 endoproteases for correct processing. In contrast, the modified form can be cleaved by ubiquitously expressed endoproteases, such as furin [56]. Conversely, expression of PC2 and PC3 in nonbeta cells results in correct processing of native proinsulin $[57,58]$. Other neuroendocrine cells considered for ectopic insulin production naturally express these enzymes.

The major obstacle to ectopic insulin expression is the difficulty of reconstructing, in non-beta cells, the highly regulated insulin secretion of the normal beta cell. A number of beta-cell proteins involved in coupling the amounts of secreted insulin to changes in the extracellular concentrations of glucose and other secretagogues have been identified, including the glucose transporter isotype GLUT2, the glucose phosphorylating enzyme glucokinase and the ATP-sensitive potassium channel [59]. Hepatocytes, which are a key cell type in the regulation of carbohydrate metabolism by insulin, and a favourite site for insulin gene therapy attempts, express GLUT2 and glucokinase. Other components involved in this complex mechanism, however, including specialized calciumbinding and $\mathrm{Ca}^{2+}$-channel molecules, and poorlycharacterized secretory vesicle and plasma membrane proteins, are not expressed in liver cells which do not have a regulated secretory pathway. Even if all the cellular components involved in regulated insulin secretion were fully characterized, the reconstruction of this entire apparatus in a non-beta cell is a prohibitive genetic engineering task. Thus it is not surprising that attempts in recent years to achieve regulated insulin secretion in vivo in such tissues as pituitary [51] and liver [53] have met with little success and produced only a limited degree of regulation. The same difficulties were encountered in engineering correctly regulated insulin secretion in non- beta cell lines in culture $[49,50,60]$. In some of the cell lines, an additional concern is the continued release of other hormones or secreted proteins, which are the natural products of those cell types, and can cause severe abnormalities if such cells are transplanted into Type I diabetic patients.

An alternative to glucose-regulated insulin release is glucose-regulated insulin gene transcription. A number of regulatory regions of genes expressed in the liver can respond to an increase in extracellular glucose concentrations by upregulating their transcriptional activity [61]. Examples include the L-type pyruvate kinase (L-PK) promoter [62] and the phosphoenolpyruvate carboxykinase (PEPCK) promoter [63]. By placing the insulin coding sequence under the control of such a promoter, it could be possible to regulate its transcription to some extent in response to changes in plasma glucose $[52,64]$. The regulation of these promoters is though rather complex and depends on insulin, in addition to glucose. They are unlikely therefore, to respond to changes in plasma glucose in Type I diabetes patients as efficiently as in non-diabetic people. Moreover, the kinetics of feedback loops based on transcriptional changes is much slower than that of the secretory response. When insulin is needed after a meal, the time required for de novo insulin biosynthesis might create a window of hyperglycaemia of several hours. In hypoglycaemia, the half life of preformed insulin mRNA will prolong the period of unregulated insulin secretion. Underproduction of insulin will maintain a dependence on exogenous insulin and overproduction will lead to dangerous hypoglycaemic episodes. Thus the risk-to-benefit balance of transcriptional regulation of insulin production is worse than that of insulin injections; it does not offer improved precision of insulin dosing and exposes the patient to the potential risks of genetic manipulations.

\section{Engineering of beta-cell lines}

The difficulty of reconstituting insulin storage and regulated secretion in non-beta cells makes exogenous beta cells the most realistic candidate cell type for replacing normal beta-cell function. Beta-cell replacement through transplantation does not fit the narrow definition of gene therapy, however, genetic modification of the transplant in vitro prior to transplantation could improve its survival, function and safety following transplantation and should therefore be considered in the context of this article.

The two main obstacles to beta-cell transplantation remain the scarcity of transplantable tissue and immunological rejection. Allogeneic pancreas transplantation has been quite successful, particularly in combination with kidney transplants $[65,66]$, however, it is severely limited by donor availability. Trans- 
plantation of allogeneic isolated islets into Type I diabetic patients suffers from the same limitation and has shown far less promise with the conventional immunosuppression regimens which cannot avoid the recurring autoimmunity $[66,67]$. With the development of novel immunoisolation approaches [68] xenogeneic islets, most notably porcine, have been considered as a more readily available source of tissue for transplantation [69-71]. Unfortunately, with the exception of one study [71], encapsulation by itself has not been able to offer long-term protection to islets transplanted into an autoimmune environment, such as the NOD mouse, without additional immunosuppressive agents [25]. Xenografts raise a number of difficult issues including a vigorous immunological rejection, physiological incompatibility and the risk of introducing new pathogens into the human population [72]. In addition, the reproducible isolation and preservation of functional pig islets on a large scale has proven to be difficult. On the positive side, xenogeneic islets could be less susceptible to recurring autoimmunity directed against human beta cells.

The shortage of transplantable beta cells can be overcome by the generation of beta-cell lines. The use of rodent beta-cell lines in diabetic animals has shown that pure beta cells can effectively replace the function of intact islets for long periods of time [73]. The hormones produced by islet non-beta cells are important for glucose homeostasis. The pancreas of Type I diabetic patients, however, contains sufficient numbers of $\alpha, \delta$, and PP cells. Apparently mutual regulation of function among the different islet cell types through cell-to-cell contacts and paracrine effects is not crucial for most aspects of glucose homeostasis as long as the endocrine feedback loops are intact.

In addition to providing an abundant source of beta cells, cell lines represent a more reproducible source, compared with islets, with respect to functional properties. Another advantage of cell lines is the ability to modify the cells by gene transfer in culture to improve their properties.

The limited understanding of the natural factors that regulate beta-cell replication at present precludes appreciable expansion of normal islet beta cells in vitro. The development of beta-cell lines has depended on the use of oncogenes to induce replication of beta cells [73-84]. Unfortunately, the experience with both rodent $[79,80]$ and human [81-84] transformed beta cells has often been disappointing due to phenotypic instability and de-differentiation. Transformed beta-cell lines tend to lose insulin biosynthesis and regulated secretion and manifest insulin release in response to subphysiological glucose concentrations. Cell replication and advanced differentiation are probably mutually exclusive in beta cells as in most other cell types. Normal, differentiated beta cells do not replicate. Cell transformation could turn off some of their differentiated functions while turning on those functions required for cell replication. In addition, the inherent genetic instability of transformed cells could lead to phenotypic changes. Some of these problems might be averted if the oncogene expression could be turned off once sufficient cell numbers have been generated, potentially inducing terminal cell differentiation. In addition, such a reversible transformation approach would allow control of cell number in vivo, which is critical for both functional and safety reasons.

Our group has developed a strategy for conditional oncogene expression in beta cells in transgenic mice [73]. This approach relies on a regulatory system for gene expression based on the bacterial tetracycline (tet) operon [85]. Using this system, we were able to tightly and reversibly regulate the expression of the SV40 T antigen (Tag) oncoprotein in beta cells [73]. The transformed beta cells depend on the continuous expression of Tag for their proliferation and the shut-off of Tag expression induces growth arrest. Thus this system enables efficient regulation of cell replication. This is in contrast to a similar model in salivary gland epithelial cells in which the cells were shown to become independent of Tag expression at a certain stage in the transformation process allowing them to continue to proliferate in the absence of Tag [86].

The effects of growth arrest on the transformed beta-cell viability and function were hard to predict a priori. On the one hand, the ability to devote their entire energy to their differentiation plan could allow the cells to improve their function. On the other hand, the forced growth arrest of transformed cells could be expected to generate conflicting signals that could lead to apoptosis. Detailed characterization of a cell line derived from this transgenic system, denoted $\beta$ TC-tet, has proven the first possibility to be correct [87]. Both proliferating and growth-arrested cells produce high amounts of insulin and secrete it in response to physiological glucose concentrations. Insulin content of growth arrested cells is, however, three to fivefold higher compared with proliferating cells [87]. The phenotype of the proliferating cells is stable for over 60 passages in culture. Eventually, the cells develop an abnormal secretory response to subphysiological glucose concentrations, which is associated with upregulation of hexokinase expression [86] as has been observed in other betacell lines $[79,80]$. This phenomenon could be related to the increased energy consumption of transformed cells for which the higher metabolic capacity of hexokinase at low glucose concentrations could provide a selective advantage. Abnormal overexpression of hexokinase represents a considerable impediment to the use of transformed beta cell lines in cell therapy. Unlike other beta-cell lines, however, in $\beta$ TC-tet cells this abnormality can essentially be corrected by growth arrest which induces a downregulation of the 
increased hexokinase activity close to the normal range [87], supporting the correlation between increased hexokinase activity and beta-cell proliferation.

The potential of the reversible transformation approach is best shown by transplantation experiments in syngeneic streptozotocin-diabetic mice. Intraperitoneal injection of $\beta$ TC-tet cells can restore euglycaemia. Treatment of the mice with tet prevents abnormal cell expansion, and the cells remain fully functional in vivo for months in the growth arrested state [73]. They are capable of resuming replication if the tet block is removed [73]. Insulin secretion in vivo is regulated by hyperglycaemia, as shown by hyperglycaemic clamp studies [87]. These results show that reversible transformation is a promising approach for growing large numbers of beta cells in culture, while providing a tight control of cell replication and improved cell function following transplantation in vivo.

Conditional transformation of isolated human islets in vitro could lead to the development of similar human beta-cell lines. With further improvements in cell encapsulation techniques this could become a realistic therapy for Type I diabetes in the near future. The concerns about using transformed cells in humans could be addressed by designing ways to eliminate the oncogenes from the cells, for example by using the Cre-loxP DNA recombination approach [88] and by introduction of suicide mechanisms into the engineered cells, such as the herpes simplex thymidine kinase gene, which will allow cell elimination in case of escape from the encapsulation device. In this respect a xenogeneic beta-cell line, perhaps one engineered to produce human insulin, is preferable to an allogeneic cell line, since escaped cells will be readily destroyed by immune rejection.

\section{Conclusion}

A number of promising genetic approaches for gene therapy and cell therapy of Type I diabetes have been developed in recent years. Additional, and perhaps better, candidate genes are likely to emerge from a more complete understanding of the genetic and environmental factors leading to Type I diabetes and of the molecular events involved in beta-cell autoimmune destruction, islet ontogeny and differentiation, and insulin production and secretion. Although much remains to be done, the rapid progress in all of these fields supports an optimistic outlook for the development of new therapies in the near future. Nevertheless, given that the current insulin therapy with all its imperfections does not carry unknown risks, the benefits offered by any novel therapy will have to be carefully weighed in balance with its potential risks.
Acknowledgements. My research has been supported by the Juvenile Diabetes Foundation International, the National Institute for Diabetes and Digestive and Kidney Diseases, by a Career Scientist Award from the Irma T. Hirschl Foundation and by the Israel Science Foundation.

\section{References}

1. Crystal RG (1995) Transfer of genes to humans: early lessons and obstacles to success. Science 270: 404-410

2. Anderson WF (1998) Human gene therapy. Nature 392: 25-30

3. The Diabetes Control and Complications Trial Research Group (1993) The effect of intensive treatment of diabetes on the development and progression of long-term complications in insulin-dependent diabetes mellitus. $\mathrm{N}$ Engl J Med 329: 977-986

4. Wicker LS, Todd JA, Peterson LB (1995) Genetic control of autoimmune diabetes in the NOD mouse. Annu Rev Immunol 13: 179-200

5. Honeyman MC, Harrison LC, Drummond B, Colman PC, Tait BD (1995) Analysis of families at risk for IDDM reveals that HLA antigens influence progression to clinical disease. Mol Med 1: 576-582

6. Tisch R, McDevitt H (1996) Insulin-dependent diabetes mellitus. Cell 85: 291-297

7. Barnett AH, Eff C, Leslie RDG, Pyke DA (1981) Diabetes in identical twins: a study of 200 pairs. Diabetologia 20: 404-409

8. Gottlieb PA, Eisenbarth GS (1998) Diagnosis and treatment of pre-insulin dependent diabetes. Annu Rev Med 49: 391-405

9. Honeyman M, Wasserfal C, Nerup J, Rossini A (1997) Prediction and prevention of IDDM. Diabetologia 40[Suppl 3]: B58-B61

10. Iwahashi H, Hanafusa T, Eguchi Y et al. (1996) Cytokineinduced apoptotic cell death in a mouse pancreatic betacell line: inhibition by bcl-2. Diabetologia 39: 530-536

11. Liu Y, Rabinovitch A, Suarez-Pinzon W et al. (1996) Expression of the bcl-2 gene from a defective HSV-1 amplicon vector protects pancreatic $\beta$ cells from apoptosis. Human Gene Therapy 7: 1719-1726

12. Corbett JA, McDaniel ML (1992) Does nitric oxide mediate autoimmune destruction of $\beta$-cells? Diabetes 41: 897-903

13. Karlsen AE, Andersen HU, Vissing H et al. (1995) Cloning and expression of cytokine-inducible nitric oxide synthase cDNA from rat islets of Langerhans. Diabetes 44: 753-758

14. Kubisch HM, Wang J, Luche R et al. (1994) Transgenic copper/zinc superoxide dismutase modulates susceptibility to type I diabetes. Proc Natl Acad Sci USA 91: 9956-9959

15. Hohmeier HE, Thigpen A, Tran VV, Davis R, Newgard CB (1998) Stable expression of manganese superoxide dismutase (MnSOD) in insulinoma cells prevents IL-1 beta-induced cytotoxicity and reduces nitric oxide production. J Clin Invest 101: 1811-1820

16. Wold WSM, Gooding LR (1991) Region E3 of adenovirus: a cassette of genes involved in host immunosurveillance and virus-cell interactions. Virology 184: 1-8

17. Efrat S, Fejer G, Brownlee M, Horwitz MS (1995) Prolonged survival of murine pancreatic islet allografts mediated by adenovirus early region 3 immunoregulatory transgenes. Proc Natl Acad Sci USA 92: 6947-6951

18. von Herrath MG, Efrat S, Oldstone MBA, Horwitz MS (1997). Expression of adenoviral E3 transgenes in $\beta$ cells 
prevents autoimmune diabetes. Proc Natl Acad Sci USA 94: 9808-9813

19. Oldstone MBA, Nerenberg M, Southern P, Price J, Lewicki H (1991) Virus infection triggers insulin-dependent diabetes mellitus in a transgenic model: Role of anti-self (virus) immune response. Cell 65: 319-331

20. Chervonsky AV, Wang Y, Wong FS et al. (1997) The role of Fas in autoimmune diabetes. Cell 89: 17-24

21. Kang SM, Schneider DB, Lin Z et al. (1997) Fas ligand expression in islets of Langerhans does not confer immune privilege and instead targets them for rapid destruction. Nature Med 3: 738-743

22. Allison J, Georgiou HM, Strasser A, Vaux DL (1997) Transgenic expression of CD95 ligand on islet $\beta$ cells induces a granulocytic infiltration but does not confer immune privilege upon islet allografts. Proc Natl Acad Sci USA 94: 3943-3947

23. Lau HT, Yu M, Fontana A, Stoeckert CJ (1996) Prevention of islet allograft rejection with engineered myoblasts expressing FasL in mice. Science 273: 109-112

24. Lenschow DJ, Zeng Y, Thistlethwaite JR et al. (1992) Long-term survival of xenogeneic pancreatic islet grafts induced by CTLA4Ig. Science 257: 789-792

25. Weber CJ, Hagler MK, Chryssochoos JT et al. (1997) CTLA4-Ig prolongs survival of microencapsulated neonatal porcine islet xenografts in diabetic NOD mice. Cell Transplant 6: 505-508

26. Khoury SJ, Akalin E, Chandraker A et al. (1995) CD28-B7 costimulatory blockade by CTLA4Ig prevents actively induced experimental autoimmune encephalomyelitis and inhibits Th1 but spares Th2 cytokines in the central nervous system. J Immunol 155: 4521-4524

27. McIntosh KR, Linsley PS, Drachman DB (1995) Immunosuppression and induction of anergy by CTLA4Ig in vitro: effects on cellular and antibody responses of lymphocytes from rats with experimental autoimmune myasthenia gravis. Cell Immunol 166: 103-112

28. Lenschow DJ, Ho SC, Sattar H et al. (1995) Differential effects of anti-B7-1 and anti-B7-2 monoclonal antibody treatment on the development of diabetes in the nonobese diabetic mouse. J Exp Med 181: 1145-1155

29. Mueller R, Krahl R, Sarvetnick N (1996) Pancreatic expression of interleukin- 4 abrogates insulitis and autoimmune diabetes in nonobese diabetic (NOD) mice. J Exp Med 184: 1093-1099

30. Balasa B, Sarvetnick N (1996) The paradoxical effects of interleukin 10 in the immunoregulation of autoimmune diabetes. J Autoimmun 9: 283-286

31. Corbett J, Serup P, Bonner-Weir S, Nielsen JH (1997) Betacell ontogeny: growth and death. Diabetologia 40: B27-B32

32. Dudek RW, Lawrence J, Hill RS, Johnson RC (1991) Induction of islet cytodifferentiation by fetal mesenchyme in adult pancreatic ductal epithelium. Diabetes 40: 1041-1048

33. Slack JMW (1995) Developmental Biology of the pancreas. Development 121: 1569-1580

34. Bouwens L, Kloppel G (1996) Islet cell neogenesis in the pancreas. Virchows Arch 427: 553-560

35. Madsen OD, Jensen J, Blume N et al. (1996) Pancreatic development and maturation of the islet B cell. Studies of pluripotent islet cultures. Eur J Biochem 242: 435-445

36. Bonner-Weir S, Baxter LA, Schuppin GT, Smith FE (1993) A second pathway for regeneration of adult exocrine and endocrine pancreas: a possible recapitulation of embryonic development. Diabetes 42: 1717-1720

37. Wang RN, Kloppel G, Bouwens L (1995) Duct-to islet-cell differentiation and islet growth in the pancreas of duct-ligated adult rats. Diabetologia 38: 1405-1411
38. Gu D, Sarvetnick N (1993) Epithelial cell proliferation and islet neogenesis in IFN-g transgenic mice. Development 118: 33-46

39. Rooman I, Schuit F, Bouwens L (1997) Effects of vascular endothelial growth factor on growth and differentiation of pancreatic ductal epithelium. Lab Invest 76: 225-232

40. Rafaeloff R, Pittenger GL, Barlow SW et al. (1997) Cloning and sequencing of the pancreatic islet neogenesis associated protein (INGAP) gene and its expression in islet neogenesis in hamster. J Clin Invest 99: 2100-2109

41. Lefebvre VH, Otonkoski T, Ustinov J et al. (1998) Culture of adult human islet preparations with hepatocyte growth factor and $804 \mathrm{G}$ matrix is mitogenic for duct cells but not for $\beta$-cells. Diabetes 47: 134-137

42. Watanabe T, Yonemura Y, Yonekura H et al. (1994) Pancreatic beta-cell replication and amelioration of surgical diabetes by reg protein. Proc Natl Acad Sci USA 91: 3589-3592

43. Mashima H, Ohhishi H, Wakabayashi K et al. (1996) Betacellulin and activin A coordinately convert amylase-secreting pancreatic AR42 J cells into insulin-secreting cells. J Clin Invest 97: 1647-1654

44. Mashima H, Shibata H, Mine T, Kojima I (1996) Formation of insulin-producing cells from pancreatic acinar AR42 J cells by hepatocyte growth factor. Endocrinology 137: 3969-3976

45. Swenne I (1983) Effects of aging on the regenerative capacity of the pancreatic $\beta$-cell of the rat. Diabetes 32: 14-19

46. Hellerstrom C, Swenne I (1991) Functional maturation and proliferation of fetal pancreatic $\beta$-cells. Diabetes 40 [Suppl 2]: 89-93

47. Hayek A, Beattie GM, Cirulli V, Lopez AD, Ricordi C, Rubin JS (1995) Growth factor/matrix-induced proliferation of human adult $\beta$-cells. Diabetes 44: 1458-1460

48. Moore H-P, Walker MD, Lee F, Kelly RB (1983) Expressing a human insulin cDNA in a mouse ACTH-secreting cell: intracellular storage, proteolytic processing, and secretion on stimulation. Cell 35: 531-538

49. Vollenweider F, Irminger JC, Gross DJ, Villa-Komaroff L, Halban PA (1992) Processing of proinsulin by transfected hepatoma (FAO) cells. J Biol Chem 267: 14629-14636

50. Simpson AM, Tuch BE, Swan MA, Tu J, Marshall GM (1995) Functional expression of the human insulin gene in a human hepatoma cell line (HEP G2). Gene Therapy 2: 223-231

51. Lipes MA, Cooper EM, Skelly R et al. (1996) Insulin-secreting non-islet cells are resistant to autoimmune destruction. Proc Natl Acad Sci USA 93: 8595-8600

52. Valera A, Fillat C, Costa C et al. (1994) Regulated expression of human insulin in the liver of transgenic mice corrects diabetic alterations. FASEB J 8: 440-447

53. Kolodka TM, Finegold M, Moss L, Woo SL (1995) Gene therapy for diabetes mellitus in rats by hepatic expression of insulin. Proc Natl Acad Sci USA 92: 3293-3297

54. Goldfine ID, German MS, Tseng HC et al. (1997) The endocrine secretion of human insulin and growth hormone by exocrine glands of the gastrointestinal tract. Nat Biotechnol 15: 1378-1382

55. Serup P, Jensen J, Andersen FG et al. (1996) Induction of insulin and IAPP production in pancreatic islet glucagonoma cells by insulin promoter factor 1 . Proc Natl Acad Sci USA 93: 9015-9020

56. Groskreutz DJ, Sliwkowski MX, Gorman CM (1994) Genetically engineered proinsulin constitutively processed and secreted as mature, active insulin. J Biol Chem 269: $6241-6245$ 
57. Vollenweider F, Kaufmann J, Irminger JC, Halban PA (1995) Processing of proinsulin by furin, PC2, and PC3 in (co)transfected COS (monkey kidney) cells. Diabetes 44: $1075-1080$

58. Kaufmann JE, Irminger J-C, Mungall J, Halban PA (1997) Proinsulin conversion in $\mathrm{GH} 3$ cells after coexpression of human proinsulin with the endoproteases PC2 and/or PC3. Diabetes 46: 978-982

59. Efrat S, Tal M, Lodish HF (1994) The pancreatic $\beta$-cell glucose sensor. Trends in Biochem Sci 19: 535-538

60. Hughes SD, Quaade C, Johnson JH, Ferber S, Newgard CB (1993) Transfection of AtT-20ins cells with GLUT2 but not GLUT1 confers glucose-stimulated insulin secretion: relationship to glucose metabolism. J Biol Chem 268: 15205-15212

61. Vaulont S, Kahn A (1994) Transcriptional control of metabolic regulation genes by carbohydrates. FASEB J 8: 28-35

62. Doiron B, Cuif MH, Kahn A, Diaz-Guerra MJ (1994) Respective roles of glucose, fructose, and insulin in the regulation of the liver-specific pyruvate kinase gene promoter. $\mathbf{J}$ Biol Chem 269: 10213-10216

63. Meyer S, Hoppner W, Seitz HJ (1991) Transcriptional and post-transcriptional effects of glucose on liver phosphoenolpyruvate-carboxykinase gene expression. Eur J Biochem 202: 985-991

64. Gros L, Montoliu L, Riu E, Lebrigand L, Bosch F (1998) Regulated production of mature insulin by non-beta-cells. Human Gene Therapy 8: 2249-2259

65. International Pancreas Transplantation Registry Newsletter (1995) 8[1]: 1-16

66. Sutherland DER (1996) Pancreas and islet transplantation: now and then. Transplant Proc 28: 2131-2133

67. International Islet Transplantation Registry Newsletter (1995) 5[1]:14

68. Lanza RP, Chick WL (1997) Transplantation of pancreatic islets. Annu NY Acad Sci 831: 321-331

69. Sullivan SJ, Maki T, Borland KM et al. (1991) Biohybrid artificial pancreas:long-term implantation studies in diabetic, pancreatectomized dogs. Science 252: 718-721

70. Lacy PE, Hegre OD, Gerasimidi-Vazeou A, Gentile FT, Dionne KE (1991) Maintenance of normoglycaemia in diabetic mice by subcutaneous xenografts of encapsulated islets. Science 254: 1782-1784

71. Sun Y, Ma MX, Zhou D, Vacek I, Sun AM (1996) Normalization of diabetes in spontaneously diabetic cynomolgus monkeys by xenografts of microencapsulated porcine islets without immunosuppression. J Clin Invest 98: 1417-1422

72. Bach FH, Fishman JA, Daniels N et al. (1998) Uncertainty in xenotransplantation: individual benefit versus collective risk. Nat Med 4: 141-144

73. Efrat S, Fusco-DeMane D, Lemberg H, Emran OA, Wang $\mathrm{S}$ (1995) Conditional transformation of a pancreatic $\beta$-cell line derived from transgenic mice expressing a tetracycline-regulated oncogene. Proc Natl Acad Sci USA 92: 3576-3580

74. Santerre RF, Cook RA, Crisel RMD et al. (1981) Insulin synthesis in a clonal cell line of simian virus 40-transformed hamster pancreatic beta cells. Proc Natl Acad Sci USA 78: 4339-4342

75. Efrat S, Linde S, Kofod H et al. (1988) $\beta$-cell lines derived from transgenic mice expressing hybrid insulin-oncogenes. Proc Natl Acad Sci USA 85: 9037-9041

76. Miyazaki J-I, Araki K, Yamato E et al. (1990) Establishment of a pancreatic $\beta$ cell line that retains glucose-inducible insulin secretion: special reference to expression of glucose transporter isoforms. Endocrinology 127: 126-132

77. Hamaguchi K, Gaskins HR, Leiter EH (1991) NIT-1, a pancreatic $\beta$-cell line established from a transgenic NOD/ Lt mouse. Diabetes 40: 842-849

78. Radvanyi F, Christgau S, Baekkeskov S, Jolicoeur C, Hanahan D (1993) Pancreatic $\beta$ cells cultured from individual preneoplastic foci in a multistage tumorigenesis pathway: a potentially general technique for isolating physiologically representative cell lines. Mol Cell Biol 13: 4223-4232

79. Efrat S, Leiser M, Surana M et al. (1993) Murine insulinoma cell line with normal glucose-regulated insulin secretion. Diabetes 42: 901-907

80. Knaack D, Fiore DM, Surana M et al. (1994) Clonal insulinoma cell line which stably maintains correct glucose responsiveness. Diabetes 43: 1413-1417

81. Soldevila G, Buscema M, Marini V et al. (1991) Transfection with SV40 gene of human pancreatic endocrine cells. J Autoimmun 4: 381-396

82. Wang S, Beattie G, Mally M et al. (1997) Isolation and characterization of a cell line from the epithelial cells of the human fetal pancreas. Cell Transplant 6: 59-67

83. Wang S, Beattie GM, Mally MI et al. (1997) Analysis of a human fetal pancreatic islet cell line. Transplant Proc 29: 2219

84. Levine F, Wang S, Beattie G et al. (1995) Development of a cell line from the human fetal pancreas. Transplant Proc 27: 3410

85. Gossen M, Bujard H (1992) Tight control of gene expression in mammalian cells by tetracycline-responsive promoters. Proc Natl Acad Sci USA 89: 5547-5551

86. Ewald D, Li M, Efrat S et al. (1996) Time-sensitive reversal of hyperplasia in transgenic mice expressing SV40 T antigen. Science 273: 1384-1386

87. Fleischer N, Chen C, Surana M et al. (1998) Functional analysis of a conditionally-transformed pancreatic $\beta$-cell line. Diabetes 47: 1419-1425

88. Sauer B, Henderson N (1989) Cre-stimulated recombination at loxP-containing DNA sequences placed into the mammalian genome. Nucleic Acids Res 17: 147-161 